\title{
A SYSTEMIC FRAMEWORK FOR IMPLEMENTATION OF TQM PROGRAMMES
}

\author{
G. S. Mwaluko and E.A.M. Mjema \\ Department of Engineering Management and Entrepreneurship \\ University of Dar es Salaam \\ P.O. Box 35131 Dar es Salaam Tanzania \\ Tel.: +255222410369 \\ Fax: +255222410114 \\ E-mail: emjema@uccmail.co.tz
}

\begin{abstract}
The purpose of this paper is to present a systemic framework for implementation of TQM program in a manufacturing organisation that produces motor vehicle components in Port Elizabeth - South Africa. The approach used included conceptualisation of the systemic framework and then involvement of the stakeholders in adding scenarios to be considered in the design and implementing the framework in the real field. The findings obtained during the implementation of the systemic framework established that reduction of scrap rate, reduction of production costs, reduction of cycle time and employee motivation could be achieved through the implementation of a Systemic Framework for the TQM programme. The TQM team was satisfied that the implementation of TQM programme using the systemic framework was relevant in their particular situation. The developed systemic framework for implementation of TQM was tested in a company that manufactures motor vehicle components. The experience gained shows that the framework has a big potential for successful implementation of TQM. The developed systemic framework has a holistic approach in implementation of TQM; in that case it can be used to guide the design and implementation of successful TQM programmes. The developed systemic framework is a holistic approach, which took on board all four basic characteristics that portray an organisation. Organisations are portrayed by four interrelated characteristics namely, organisational processes, organisational design, organisational culture and organisational politics. For a successful implementation the TQM intervention should take into consideration these four characteristics.
\end{abstract}

Key words: Characteristics of organisations, systemic framework, TQM

\section{INTRODUCTION}

Quality improvement programmes, particularly TQM, have attracted many writers and practitioners because it has been shown that they improve customer satisfaction, which results into increased sales and profit to the organisations. Crosby (1979) states that the implementation of quality programmes can increase profit by $5 \%$ to $10 \%$ of sales while Juran (1988) states that quality can prevent loss of sales, reduce cost of quality, and, prevent any loss of life due to accidents. He writes that since the cost of poor quality is between $20 \%$ and $40 \%$ of sales, TQM programmes can help organisations save the same amount in sales. Also, it has been stated that TQM programmes improve productivity. It is held that improvement in productivity is possible because of the decrease in the cost of quality, decrease in throughput time and increase in employee morale.

Though many organisations invested a lot to improve productivity through TQM programmes, such efforts have been reported to bear poor results (Schaffer and Thomson, 1992; Jackson, 1995). Various writers came out with explanations for the failure of these programmes. Some have argued that TQM programmes fail because they lack proper structures to guide their implementation (Jackson, 1995). Others have suggested that the programmes fail because they are incremental and not radical (Hammer and Champy, 1993). Yet others have pointed out that the programmes are not successful because they target 
too much on processes and ignore strategic issues, and that they often treat processes as unconnected islands (Garvin, 1995; Sousa and Voss, 2002; Sitkin et al., 1994).

Regarding the failure of TQM programs, Masterson $\&$ Taylor (1996) came into conclusion that, despite the fact that TQM givens attention to the systems and processes within an organization, it virtually ignores the role of the individual, who are the main potential source of quality improvement. Wilkinson et al. (1998) argue that TQM has often failed to fulfil its promise mostly due to a lack of attention to such HRM issues. Hua et al. (2000) also came into conclusion that employees' involvement is viewed as a key factor for successful TQM implementation. Similarly Hung and Yi (2004) contend that process alignment and people involvement are two key concepts for successful implementation of TQM. In that aspect Soltani et al., (2004) argue that the main problem that many of the TQM organizations are facing is the lack of a systematic approach to solving and tackling the quality problems.

Soltani et al., (2004) argue that the organizational effectiveness in the context of TQM is mainly based on the capacity to balance the conflicting approaches of quality and HR management through the value-added feature central to TQM philosophy. They (ibid.) further argue that managers can gain competitive advantage if they are able to recognize that organizational performance is a function of both individual employees as well as system factors. A number of authors contend that the success of TQM as an all-pervasive management philosophy relies on continuous improvement of performance and eliminating obstacles to that improvement through management of process quality as a holistic approach to organizational improvement. In this case the entire organization is considered a system of interlocking processes (Sousa and Voss, 2002; Sitkin et al., 1994). However, some of the TQM failures might not be necessarily failure but the problem of measurement of TQM performance. The measurement of TQM performance is recognized to be difficult due to uncertainty regarding the time at which performance should be measured and also due to problems associated with publicly reporting the indices of performance, like market share and profitability (Taylor and Wright, 2003).
A study of TQM success factors in the UK showed that the factors that contributed to the successful implementation of TQM were mainly four: Effective leadership, Application of best practice, Economic survival, Market orientation, and Employee involvement (Warwood and Roberts, 2004). Similarly Augus (2004) found that employee focus, training, customer focus, benchmarking and top management support were key factors for a successful implementation of TQM. Hwang and Chou (2004) argue that successful implementation of TQM requires an appropriate and holistic approach. They decided to adopt a systematic approach because of its high potential for success. Hwang and Chou (2004) insisted that despite extensive structured methodology on quality management or business process improvement management issued by organizations and academics, the wider environment should be considered during implementation to ensure the best effect.

In this paper a review of causes that make TQM programmes fail is made and a systemic approach for a successful implementation of TQM Program is proposed. The analysis of the root cause for the failure of TQM programmes is based on analysing the basic four characteristics of organisation. Efforts have been made to guide the design and implementation of TQM programmes basing on the characteristics of organisation.

The main objective of the research is to develop a framework that will assist in implementation of TQM programmes. In that case, it was important to identify factors that causes TQM program to fail, and then propose a framework that will assist in eliminating those factors.

\section{BACKGROUND}

The characteristics of organisation refer to essential features that portray image of an organisation, which Flood (1996) termed as key dimensions of organisation. The characteristics include organisational processes, organisational design, organisational culture, and organisational politics. In this aspect, organisational processes refer to the flows and controls from suppliers right through to consumers including stakeholders with an interest in events. Organisational design within which processes flow refers to the degrees and forms of structure in 
terms of which patterns of coordination and control are created. There is a need to appreciate individual and cultural differences and similarities that exist between people that come into play in the decision making process. Despite this differentiation, or even because of it in some circumstances, cohesion may be attained (Flood, 1996). This is partly because it is possible to share symbols for meaningful communication. Organisational culture will refer to the cohesion between individual culture differences and similarities.

Jackson (1995) identifies similar characteristics when he contends that it is not clear what factors make organisations reasonable places to work in. He (ibid.) is not sure whether it is getting the structure right or the processes right or the culture right, or dealing with politics or probably something of combining all these things. Hence, a systemic management intervention requires taking into cognizant all four characteristics of organisation. But, this is not normally the case as most writers tend to take a fragmented approach in perceiving the causes of failure and hence, the design of TQM programmes.

A good number of authors made extensive literature review regarding the implementation of TQM. Most of the literature analysed discussed the factors affecting the implementation of TQM (Sila and Ebrahimpour, 2003; Mehra et al., 2001; Tamini, 1995; Brenda et al.,1995). Regarding the information obtained from these studies, it seems that critical organizational characteristics must be analysed to judge an organization's readiness to implement a successful TQM programme.

Although there are TQM programmes which focus on improving business processes, (Deming, 1986; Crosby, 1979; Juran, 1988) and those programmes which pay attention on improving the nature of products offered (Hauser and Clausing, 1988), yet there are features which seem to be applicable to all of them. For instance, all TQM programmes:

- Make use of quality teams or quality cycles;

- Call for management commitment;

- $\quad$ Emphasize employee training;

- $\quad$ Focus on continuous improvement;

- $\quad$ Outline goals and policies for quality; and

- $\quad$ Provide framework for achieving quality goals e.g. the PDCA cycle (Deming, 1986), the half life framework (Schneiderman, 1988), the house of quality framework (Hauser and Clausing, 1988).

It is held that if a quality programme with the above features is implemented, then customers are likely to be satisfied and quality of work life of employees improved (Ackoff, 1994). The net effect is improvement in productivity and financial performance of the organisation. But, it has been established that in many cases TQM programmes with the above features fail to produce improvements in both productivity and financial performance. For instance, Schaffer and Thomson (1992) write that:

"In a 1991 survey of more than 300 electronics companies, sponsored by the American Electronics Association. $73 \%$ of the companies reported having a total quality programme underway, but of these, $63 \%$ had failed to improve quality defects by even as much as $10 \%$. We believe this survey understates the magnitude of the failure of activity centred programmes not only in quality conscious electronics industry but, across businesses."

Schaffer and Thomson (1992) argue that the failure of TQM programmes to improve productivity is caused by the activity-based fallacy, which is adopted in implementing these programmes. They state that this fallacy advances a managerial philosophy or style such as inter functional collaboration, middle management empowerment, or employee involvement, measurement of performance such as benchmarking, assessment of customer satisfaction or statistical process control. It seems Schaffer and Thomson (1992) relate the failure of TQM programmes to their emphasis on organisational culture at the expense of organisational processes.

Garvin (1995) identifies three factors that make TQM programmes fail. The first factor is that TQM programmes assume that process design can be divorced from rethinking business strategy. TQM programmes take an operational view by targeting processes that have grown with little rationale. $\mathrm{He}$ (ibid.) maintains that in an era of volatile and rapid changing markets and technologies, TQM programmes can generate an improved process for competing in an environment that no longer exists. The second factor for the failure of TQM programmes 
is that they often treat processes as unconnected islands. In that connection, Garvin (1995) argues that the success of most businesses depends on how a bundle of their critical processes interact. Finally, Garvin (1995) writes that TQM programmes ignore management processes - the ways senior managers make decisions, communicate, implement, monitor and compensate performance. Finally, he (ibid.) concludes that TQM programmes fail because they do not take on board issues related to organisational processes particularly the environment, interaction and feedback of decisions and actions of taken by people involved in the implementation.

Lawler and Mohman (1985) take a different view on the causes of failure of quality circles and hence, TQM programmes. They argue that quality circles are unstable organisation structures that are likely to self-destruct. They identify a maximum of six phases, which any quality circle has to go through during its whole life. The phases include: start up, initial problem solving, approval of initial suggestions, implementation, expansion of problem solving and decline. According to Lawler and Mohman (1985), since all quality circles undergo decline in their lives then, it is therefore expected that TQM programmes should eventually burnout. It can be inferred that Lawler and Mohman (1985) relate the failure of TQM programmes to the lack of consideration of issues related to organisational design i.e. the need to design quality cycles such that they do not burn out.

Grant et al., (1994) argue that TQM programmes fail because there is a disagreement over goals and implementation procedures. The upper level management turns their attention to other priorities, and employees become increasingly sceptical about organisational commitment to the programmes. The reasons for the failure of TQM programmes given by Grant et al. (1994) tend to be related to conflict of issues related to values and beliefs that arises in the organisation during the implementation of TQM programmes. Values and beliefs are certainly related to organisational culture (Schein, 1988).

Jackson (1995) identifies six factors that make TQM programmes fail. According to him, TQM programmes fail because they focus on customers often at the expense of other stakeholders. Building on the work of Ackoff (1994), Jackson (1995) holds that customers often do not know what they want unless you help them discover this and, moreover other stakeholders such as employees are even more important than customers. The second cause for the failure of TQM programmes is hinged on their insistent for continuous improvement, usually by getting rid of what you do not want. Again, drawing from the work of Ackoff (1994), Jackson writes that one cannot automatically get what he/she wants by getting rid of what you do not want. He (ibid.) also agues that continuous improvement is sometimes not enough instead, one needs to undertake more drastic improvements.

The third factor for the failure of TQM programmes according to Jackson (1995) is lack of organisation structure to make quality improvement happen. The fourth factor is related to the inability of introducing quality culture and the fifth factor is related to organisation politics. On the later, Jackson (1995) writes that there is a neglect of the politics of quality and little recognition that quality interventions can lead to some groups benefiting and others suffering. Finally, Jackson maintains that while quality programmes can help us do our things but, they cannot lead us do the right things. According to Jackson (1995), TQM programmes fail because they fail to consider issues related to organisational processes, organisational design, organisational culture and organisational politics.

The conclusion drawn from the above discussion is that with the exception of Jackson (1995), most writers identify causes for the failure of TQM programmes that are related to only one and not to all four characteristics of organisation. In addition, though Jackson (1995) relates the failure of TQM programmes to all four characteristics, but he does not propose an implementation framework for TQM programmes that takes on board all four characteristics of organisation. It is proposed that the causes for the failure of TQM programmes must be related to all four characteristics of organisation because:

- It is difficult to know which characteristics are relevant in a particular situation; and

- The characteristics influence each other in a complex way. For instance, organisational processes influence the manner in which organisations are designed, they also determine 
the kind of culture, reporting systems and hence, the way power is distributed in the organisation. In the same token, organisational culture also influences the other three characteristics. The same applies to organisational politics.

A framework for the implementation of TQM programmes that takes into consideration all characteristics is therefore necessary if we are to increase the chance of success of these programmes. The authors hold that in order for a TQM programme to take into account organisational processes it must:

- $\quad$ Consider the larger environment;

- Take into consideration issues related to interaction and feedback; and

- Be robust to uncertainty.

And, in order for the TQM programme to deal with organisational culture it needs to:

- $\quad$ Facilitate the creation of a shared understanding of the problem; and

- $\quad$ Ensure that all relevant stakeholders participate in the intervention process.

In order for the TQM programme to deal with organisational design issues it must:

- Identify an appropriate structure to guide the interaction process; and

- Put into place all channels of communication.

Finally, in order for the TQM programme to deal with organisational politics it must:

- Facilitate the stakeholders to challenge the adequacy of the predominant basic assumptions; and

- Help stakeholders uncover any resource and authority related issues that can make the design and implementation of the programme difficult.

\section{METHODOLOGY}

The proposed systemic framework was used to implement a TQM programme in a manufacturing organisation that produces motor vehicle components in Port Elizabeth - South Africa. Senior managers nominated a team of eight line managers who were to spearhead the implementation process. The line managers came from different eight departments ranging from technical to management departments. The participants working as a team identified four scenarios that are likely to occur in three years time. The scenarios were worded in the following way:

A very bright scenario - in this case the demand of locally made motor vehicles will continue to increase. This will be coupled by a high increase in import taxes for imported motor vehicles and thus, discouraging potential customers to import vehicles from offshore. The organisation will also get large orders of motor vehicle components from offshore manufacturers particularly from Southern America.

A bright scenario - in this case the relation between the trade unions and management will improve for the better and hence, make the occurrence of industrial actions unlikely which would have affected the organisation's performance negatively. This will be coupled by a low increase in import taxes for imported motor vehicles by the Government and thus, slightly discouraging potential customers to import vehicles from offshore. There will also be a small amount of motor vehicle components that will be ordered by international manufacturers.

A gloomy scenario - in this case scenario the suppliers of raw material and semi-finished components will continue to struggle to keep up with demand. This will be accompanied by a moderate improvement in relation between the trade unions and management. The improvement in relations will make industrial actions unlikely to take place.

A very gloomy scenario - in this scenario there will be an increase in competition from other local motor vehicle component manufacturers thus, affecting negatively the profitability and growth of the organisation. This will be accompanied by worsening of the relation between the trade unions and management. The worsening in relations will pave a way for industrial actions to take place very frequently and thus, affecting productivity negatively.

\section{THE SYSTEMIC FRAMEWORK}

The developed systemic framework is made up of seven stages as shown in figure 1. The first stage 
involves formation of a team. It is such a team that implements the remaining six stages. The second stage comprises ascertaining the relevance of a TQM programme. This involves undertaking scenario construction and identifying key competing capabilities. A key competing capability is an activity that an organisation must excel in if it is to improve its performance. The relevance of a TQM programme is ascertained if such a programme can help create the identified key capabilities. This paper adopts an approach proposed by Schoemaker (1992; 1995) in constructing scenarios.

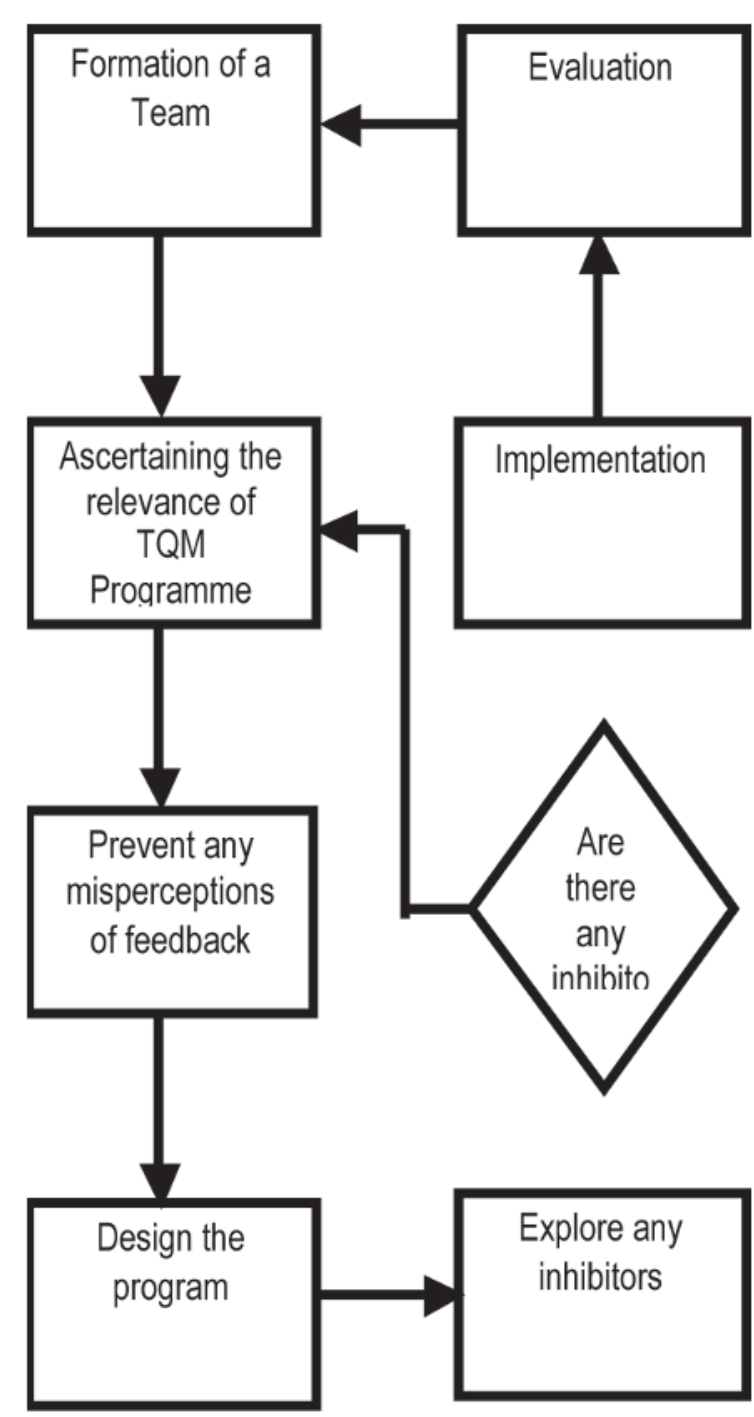

Figure 1: A Systemic Framework for the Implementation of TQM Programmes
The third stage of the framework involves prevention of misperceptions of feedback. This requires taking a total process approach in the implementation of a TQM programme. The fourth stage involves the design of a TQM programme. It comprises the identification of all activities and their timing that should be undertaken in the implementation process. It also requires identifying the kind of organisation structure that can be used to implement the programme.

Identification of inhibitors that can make the implementation of the first four stages of the framework difficult is done in the fifth stage. This involves identifying any existing assumptions and practices (issues related to ideological power) held by the organisation that can act as stumbling blocks to the implementation of the programme. It also involves dealing with issues related to personal power i.e. identifying any resource or authority related issues that can affect negatively the implementation of the programme.

\section{Formation of a Team}

Micro teams from each department were formed. A leader of each micro team from the departments joined the line managers' team.

\section{Ascertaining the relevance of TQM programme}

Ulrich's (1987) boundary judgment questions were employed to surface issues related to both ideological and personal power to ascertain the relevance of TQM programme. Two kinds of questions are used in this regard: questions that address what took place and questions that address what should have taken place.

Questions that address what took place:

1) Who selected the participants?

2) Who were the participants?

3) How did the participants work?

4) What assumptions did the participants make?

5) What expertise relevant to the intervention process the participants possessed?

6) What authority did the participants possess?

7) What resources did the participants possess?

8) What guaranteed the ownership of such expertise, authority and resources? 
Questions that address what should have taken place:

1) Who should have selected the participants?

2) Who should have been the participants?

3) How should have the participants worked?

4) What assumptions the participants should have made?

5) What expertise relevant to the intervention process the participants should have possessed?

6) What authority the participants should have possessed?

7) What resources the participants should have owned?

8) What should have guaranteed the ownership of such expertise, authority and resources?

Identification of inhibitors is done by comparing the answers given to the questions that address what took place and the answers to questions that focus on what should have taken place. Once the inhibitors are identified the team must then inform itself of the effects of these inhibitors on the effectiveness of the designed TQM programme. The programme is not implemented and evaluated (stage six and seven respectively) unless the inhibitors are identified and eliminated. Otherwise, the process should be repeated as shown in figure 1.

Two competing segments i.e. large scale and smallscale customers were identified. The required capabilities for each competing segment - scenario combination were also identified. To facilitate the identification of capabilities, the following question was used: Given this scenario - competing segment combination, what should the organization do in order to achieve organizational objectives? The identified capabilities are shown in table 1 . The capabilities with the number of times they appear in the table were also identified (as indicated in brackets).

- $\quad$ Reduction of scrap rates (7)

- $\quad$ Reduction of production costs (5)

- Reduction of cycle time (4)

- $\quad$ Employee motivation (4)

- $\quad$ Increase marketing efforts (4)

- $\quad$ Improve machine availability (4)

- $\quad$ Rethink purchasing procedures (2)

- $\quad$ Employee training (1)

\section{Table 1: Identification of capabilities}

\begin{tabular}{|c|c|c|c|c|}
\hline $\begin{array}{l}\text { Competing } \\
\text { Segment }\end{array}$ & $\begin{array}{l}\text { Very bright } \\
\text { Scenario } \\
\text { Reduction of cycle time } \\
\text { Improve machine } \\
\text { availability } \\
\text { Reduce scrap rates } \\
\text { Employee motivation } \\
\text { Employee training }\end{array}$ & $\begin{array}{l}\text { Bright } \\
\text { Scenario } \\
\text { Reduce scrap } \\
\text { rates } \\
\text { Improve machine } \\
\text { availability } \\
\text { Reduction of } \\
\text { cycle time. }\end{array}$ & $\begin{array}{l}\text { Gloomy } \\
\text { Scenario } \\
\text { Employee } \\
\text { motivation } \\
\text { Reduction of } \\
\text { production costs } \\
\text { Increase marketing } \\
\text { efforts } \\
\text { Reduce scrap rates. }\end{array}$ & $\begin{array}{l}\text { Very Gloomy } \\
\text { Scenario } \\
\text { Rethink purchasing } \\
\text { procedures } \\
\text { Reduce production costs } \\
\text { Reduce scrap rates } \\
\text { Increase marketing efforts. }\end{array}$ \\
\hline Small Scale & $\begin{array}{l}\text { Reduction of scrap rates } \\
\text { Employee motivation } \\
\text { Reduction of cycle time } \\
\text { Reduction of } \\
\text { production costs } \\
\text { Improve machine } \\
\text { availability. }\end{array}$ & $\begin{array}{l}\text { Reduction of } \\
\text { scrap rates } \\
\text { Reduction of } \\
\text { cycle time } \\
\text { Improve machine } \\
\text { availability. }\end{array}$ & $\begin{array}{l}\text { Employee } \\
\text { motivation } \\
\text { Increase marketing } \\
\text { efforts } \\
\text { Reduce scrap rates } \\
\text { Reduce production } \\
\text { costs. }\end{array}$ & $\begin{array}{l}\text { Rethink purchasing } \\
\text { procedures } \\
\text { Increase marketing efforts } \\
\text { Reduce production costs. }\end{array}$ \\
\hline
\end{tabular}


Based on table 1, it was established that reduction of scrap rate, reduction of production costs, reduction of cycle time and employee motivation, which appeared to be the key capabilities, could in fact be achieved through the implementation of a TQM programme. The team was therefore satisfied that the implementation of such a programme was relevant in their particular situation.

\section{Prevention of misperceptions of feedback}

It was decided to deal with a total process i.e. a process that incorporates suppliers' right through to the customers. Performance improvement was therefore done at this level. This approach is similar to that used in new product development.

\section{Designing the programme}

Schneiderman's (1988) framework was adopted to facilitate the implementation of the programme. Also a matrix structure to be used in the implementation process was proposed. An action plan was laid down that showed the kind of activities, the timing of these activities and the respective responsible members of the team to accomplish them. The action plan stretched over a period of six months.

\section{Identification of inhibitors}

Using the aforementioned set of questions (i.e. questions that address what took place and questions that address what should have taken place) the team felt that:

- The programme was unlikely to produce successful results because of the nature of participants that were involved in the intervention process. The team held that having line managers as participants was likely to result into poor quality of assumptions made and data that were used during the second stage of the framework. It was proposed that senior managers should also participate in the exercise.

- Having line managers as the only participants was likely to make the implementation of the programme difficult because most of them did not have access to resources due to their limited power in terms of authority. Hence, the success of the programme was perceived to solely depend on the commitment of senior managers. Such situation, the team claimed, made similar programmes fail in the past.

- Lack of representation of other stakeholders particularly customers, the department of trade and industry, regulatory bodies, suppliers and trade unions was perceived to negatively affect the quality of information used in the process and even the quality of the assumptions made. It was therefore held that this situation was likely to make the programme fail.

- $\quad$ Focusing solely on TQM programme and neglecting other type of improvement programmes that are strategic in nature such as marketing may also make the intervention fail to produce successful results.

The team suggested that the first four stages of the framework must be repeated by taking the above issues into consideration. They recommended that until the above inhibitors are sorted out, the designed TQM programme should not be implemented.

\section{Implementation}

Because of the four inhibitors identified in stage five, it was decided to first address the inhibitors before implementing the programme. To address the inhibitors the following was done:

a) Involvement of senior managers in the process; and

b) Involvement of other stakeholders such as customers, the department of trade and industry.

The draft document was presented to a team of senior managers of Departments where line mangers work. Their comments were incorporated into the document. In order for the process to be cost effective, questionnaires were used to gather views of stakeholders under item (b) above. Since the company produces motor vehicle components that are sold to various car manufactures such as Ford Motors, Nissan, Volkswagen and Toyota, questionnaires were sent to these companies. Views from the Department of Trade and Industry were also sought through structured interviews. After colleting the view of various stakeholders the implementation process, which stretched over a period of six months commenced. 
Evaluation

After the six months period an evaluation process started. The evaluation process revealed the following:

- Quality improvements in some Departments were significant than in other Departments. The cause was the existence of differences in complexity of Departments. Complex departmentsexperiencedmodestimprovements in quality. It was decided that in setting quality goals, managers should acknowledge the effect of Departmental complexities.

- Lack of a wide spectrum of stakeholder involvement in the beginning made the implementation efforts to be rather inefficient though effective. It was decided to correct this in future improvement efforts.

\section{CONCLUSION}

In this paper various reasons for TQM failure in implementation were analysed. It was found that TQM programmes fail because they do not consider all the four characteristics of organisation i.e. organisational processes, design, culture and organisational politics. A systemic framework for the implementation of TQM programmes that takes on board all four characteristics was put forth. Through the implementation of the systemic framework it was established that reduction of scrap rate, reduction of production costs, reduction of cycle time and employee motivation, which appeared to be the key capabilities, could be achieved during the implementation of a TQM programme. The TQM team was satisfied that the implementation of the developed systemic framework was relevant in their particular situation.

\section{REFERENCES}

Ackoff, L.R. (1994), The Democratic Corporation, Oxford University Press, Oxford

Augus, A. (2004), “TQM as a Focus for Improving Overall Service Performance and Customer Satisfaction, Empirical Study on a Public Service Sector in Malaysia", Total Quality
Management, Vol. 15 No. 5/6, pp. 615-628

Brenda W., Helms, M. and Ettkin L.P. (1995), "Is your Organization ready for TQM? An assessment methodology", The TQM Magazine, Vol. 7 No. 5, pp. 43-49.

Crosby, P.B. (1979), Quality is free, The art of making quality certain, McGraw Hill, New York, NY.

Deming, W.E. (1986), Out of Crisis, MIT Centre for Advanced Engineering, Cambridge, MA.

Flood, L.R. (1996), Total Systems Intervention, Local Systems Intervention. In Flood R. L and Romm, N. A (eds.), Critical Systems Thinking, Current Research and Practice, Plenum, New York.

Garvin, D.A. (1995), "Leveraging Process for Strategic advantage", Harvard Business Review, September - October, pp. 77 -90.

Grant, R. M., Shani, R. and Krishman, R. (1994), "TQM's Challenge to Management Theory and Practice", Sloan Management Review, Winter, pp. 25 - 35.

Hammer, M. and Champy, J. (1993), Reengineering the Corporation: A Manifesto for Business Revolution, HarperBusiness, New York, NY

Hauser, J. R. and Clausing, D. (1988), “The House of Quality", Harvard Business Review, May June, pp. 63 - 73.

Hua, H., Chin, K. S., Sun, H. and Xu, Y. (2000), "An Empirical Study on Quality Management Practices in Shanghai Manufacturing Industries", Total Quality Management, Vol. 11 No. 8, pp. 1111-1122.

Hung, R.Y. and Yi, C. (2004), "The Implementation of Total Quality Management Strategy in Australia, Some Empirical Observations", The Journal of American Academy of Business, pp. $70-74$.

Hwang, I-S. and Chou, C-L. (2004), “A Systematic Approach to Optimizing Business Processes 
beyond ISO 9000, A Taiwanese Case Study", International Journal of Management, Vol. 21 No. 3, pp. $349-360$.

Jackson, M.C. (1995), "Beyond the Fads, Systems Thinking for Managers", Systems Research, Vol. 12 No.,1 pp. 25 - 42.

Juran, J. M. (1988), Juran on Planning for Quality, The Free Press, New York, NY.

Lawler, E.E. and Mohman, S.A. (1985), "Quality Circles after the fad", Harvard Business Review, January - February, pp. 65-71.

Masterson, S. S. and Taylor, M. S. (1996), "Total quality management and performance appraisal, an integrative perspective", Journal of Quality Management, Vol. 1 No. 1, pp. $67-$ 89.

Mehra, S., Hoffman, J.M. and Sirias, D. (2001), "TQM as a management strategy for the next millennia”, International Journal of Operations and Production Management, Vol. 21 No. 5/6, pp. 855-876.

Schaffer, R.H. and Thomson, H.A. (1992), "Successful Change Programmes Begin With Results", Harvard Business Review, January February, pp. 80 - 89.

Schneiderman, A.M. (1988), "Setting Quality Goals”, Quality Progress, April, pp. 51 - 56.

Schein, E.H. (1988), Organisational Culture and Leadership. The Jossey - Base Inc.

Schoemaker, P.J.H. (1992), "How to Link Strategic Vision to Core Capabilities", Sloan Management Review, Fall, pp. 67 - 81.

Schoemaker, P.J.H. (1995), "Scenario Planning, A Tool for Strategic Thinking", Sloan Management Review, Winter, pp. 25 - 33.

Sila, I. and Ebrahimpour, M. (2003), "Examination and comparison of the critical factors of total quality management (TQM) across countries", International Journal of Production Research, Vol. 41 No.2, pp. 235-268.

Sitkin, S-B., Sutcliffe. K. and Schroedern, R. G. (1994), "Distinguishing control from learning in Total Quality Management, a contingency perspective", Academy of Management Review, Vol. 19 No. 3, pp. 537-564.

Soltani, E.,Van der meer, R.B., Williams, T.M. (2004), "Challenges Posed to Performance Management by TQM Gurus, Contributions of Individual Employees Versus SystemsLevel Features", Journal of Total Quality Management, Vol. 15 No. 8, pp. 1069-1091.

Sousa R. and Voss, C. A. (2002), "Quality management re-visited, a reflective review and agenda for future research", Journal of Operation Management, Vol. 20 No. 1, pp. 91-109.

Tamini, M. (1995), “An empirical investigation of critical factors using exploratory factor analysis", International Journal of Production Research, Vol. 33 No. 11, pp. 3041-3051.

Taylor, W.A. and Wright, G. H. (2003), "A longitudinal study of TQM implementation, factors influencing success and failure", Omega, The international journal of management science, Vol. 31, pp. 97-111.

Ulrich,W.(1987), “Critical heuristics of social system design", European Journal of Operational Research, Vol. 31, pp. $276-283$.

Wilkinson. A., Redman, T., Snape, E. and Marchington, M. (1998), Managing with Total Quality Management, Theory and Practice, Macmillan Press, London

Warwood, S.J. and Roberts, P.A.B. (2004), "A Survey of TQM Success Factors in the UK", Total Quality Management, Vol. 15, No. 8, pp.1109-1117 